\title{
SOBRE A TEMÁTICA "RESPONSABILIDADE SOCIAL" NA LITERATURA DA CIÊNCIA DA INFORMAÇÃO INDEXADA PELA BRAPCI ${ }^{1}$
}

\author{
Isa Maria Freire \\ Doutora em Ciência da Informação pela Universidade Federal do Rio de Janeiro - UFRJ \\ Professora do Departamento de Ciência da Informação da Universidade Federal da Paraíba - UFPB \\ E-mail: isafreire@globo.com
}

\begin{abstract}
Resumo
Apresenta resultados de pesquisa sobre emergência de produção científica publicada em periódicos sobre a temática <responsabilidade social> no campo da Ciência da Informação, no Brasil. Discorre sobre o contexto teórico das ciências sociais e o modelo de rede conceitual proposto por Wersig (1993) para a Ciência da Informação. Relata o processo de pesquisa, que adotou o método indiciário e o brauseio como instrumentos para a identificação dos indícios de produção sobre a temática na literatura indexada pela Base de Dados Referencial de Artigos de Periódicos em Ciência da Informação - Brapci. Conclui que nos últimos 13 anos a produção sobre a temática vem crescendo na literatura brasileira, em número de autores e artigos, os quais abordam temas relacionados à epistemologia (responsabilidade social como fundamento da Ciência da Informação), à teoria (ações de política e gestão na sociedade da informação) e da aplicação (em unidades e para profissionais da informação).
\end{abstract}

Palavras-chave: Ciência da Informação - Responsabilidade social. Literatura científica - Brasil. Paradigma indiciário. Brapci.

\section{ON THE THEMATIC "SOCIAL RESPONSIBILITY" IN THE LITERATURE OF INFORMATION SCIENCE INDEXED BY BRAPCI}

\begin{abstract}
Presents the results of research on the emergence of output on topics <social responsibilities> in the field of information science in Brazil. Discusses the theoretical context of the social sciences and the conceptual network model proposed by Wersig (1993) for Information Science. Reports the research process, which adopted the method and evidential browsing as tools to the identification of producing evidence on the issue in the literature indexed by Database Referential Journal Articles in Information Science - Brapci. Concludes that in the last 13 years the production on the topic is growing in Brazilian literature in the number of authors and articles, which address issues related to epistemology (social responsibility as the foundation of Information Science), theory (policy actions and management in the information society) and application (in units and information professionals).
\end{abstract}

Keywords: Information Science - Social responsibility. Scientific literature - Brazil. Evidential paradigm. Brapci.

\section{Introdução}

A presente comunicação compartilha o processo e os resultados de pesquisa exploratória para busca de indícios de abordagens da temática <responsabilidade social> na literatura científica brasileira indexada pela Base de Dados Referencial de Artigos de

\footnotetext{
${ }^{1}$ Baseado em trabalho apresentado em evento científico em nível nacional, em 2013, cujo texto foi revisto para a presente publicação.
} 
Periódicos em Ciência da Informação - Brapci, publicada pela Universidade Federal do Paraná. Trata-se de um exercício teórico-metodológico suscitado por reflexões epistemológicas acerca da premissa de uma responsabilidade social como fundamento para a Ciência da Informação como proposto por Wersig e Neveling (1975) e corroborado por Freire (2001).

O exercício se insere no âmbito da pesquisa de produtividade "Reflexão: ação relacional inter-meta-pós-mediática no Laboratório de Tecnologias Intelectuais - LT $i$ ”, em desenvolvimento na Universidade Federal da Paraíba, no que diz respeito ao contexto das questões que orientam as ações de informação no campo da pesquisa. Neste exercício, a questão principal diz respeito à emergência de produção científica sobre a temática <responsabilidade social> no campo da Ciência da Informação, no Brasil. Nossa hipótese de trabalho é que as publicações sobre a temática em estudo vêm crescendo na literatura da área, no Brasil, e esse crescimento é liderado por autores que abordam essa temática em seus problemas de pesquisa, compartilhando os resultados na literatura da Ciência da Informação.

Para identificar as publicações e autores que abordam essa temática, bem como os temas de suas comunicações no território da literatura, recorremos ao método indiciário e ao procedimento de brauseio, descrito por Araújo (1994), no quadro das tags que representam "termos associados à descrição de busca para filtrar informações relevantes", na interface de resultados da Brapci.

Destarte, orientamos nosso olhar sobre o território a partir do modelo de regime de informação de González de Gómez (2003b, p.61), para o qual a informação é definida como "ações de informação, as quais remetem aos atores que as agenciam aos contextos e situações em que acontecem e aos regimes de informação em que se inscrevem". Por sua vez, as ações de informações se desenvolvem em domínios diferentes do regime de informação, como González de Gómez descreve em sua teleologia das ações de informação (2003a) e Freire (2012) caracteriza em sua análise dos estratos e modalidades das ações de informação no LTi.

Os indícios resultantes da nossa busca representam os fios conceituais com os quais tecemos um mapa da produção na temática <responsabilidade social> no território da literatura brasileira do campo da Ciência da Informação. A partir da reunião desses indícios em uma trama cujo sentido é reconhecível à luz do modelo teórico que adotamos, oferecemos uma resposta ao problema que inspirou a pesquisa, corroborando nossa hipótese de trabalho. Certamente trata-se de uma resposta provisória, condicionada pelo tempo, espaço e instrumentos da pesquisa. Contudo, esperamos provocar a curiosidade e interesse que propiciem novas incursões sobre esta e outras temáticas no território da literatura da Ciência 
da Informação.

\section{$2 \mathrm{O}$ tear conceitual}

Para Bunge (1980, p.160), as ciências sociais não oferecem "teorias" sobre seu objeto de estudo, sendo mais comum encontrarmos quadros teóricos, ou "contexto", que ele define como "conjunto de proposições referentes a um mesmo domínio (p.ex., sociedades humanas) contendo certos conceitos (p.ex., os de classe social e anomia) que constituem um grupo homogêneo, no sentido de que todos eles se referem ao mesmo domínio”. Sem ser propriamente uma teoria, o contexto possuiria um grau de organização superior ao de um conjunto de proposições tomadas ao acaso, podendo ser negadas ou combinadas sem que desse processo resultem proposições estranhas ao próprio contexto.

[...] Um contexto serve, então, de matéria-prima para elaboração de teorias, uma vez que obteremos cada uma destas selecionando proposições do contexto e, em particular, guardando tão somente aquelas que constituam um conjunto coerente (não contraditório). (BUNGE, 1980, p.160)

Destarte, o contexto contém a possibilidade da teoria, oferecendo uma explicação para eventos e relações observados em um dado campo de pesquisa e uma previsão para a ocorrência de eventos e relações ainda não observados, com base nos seus próprios princípios explanatórios. Sobre o assunto, Bunge (1980) lembra que embora represente um modo eficaz de explicar os fatos observados, as teorias têm caráter provisório, sendo aceitas na medida de sua coerência semântica e do valor de verdade de suas predições. Nesse sentido, toda teoria, e por extensão todo contexto, em última instância são relativos a uma problemática, o que significa que devem se referir efetivamente à realidade que visa interpretar, pois nas palavras de Popper (1972 citado por SARACEVIC, 1996, p.40) "não somos estudantes de assuntos, mas estudantes de problemas. E os problemas constituem os recortes de qualquer assunto ou disciplina". No campo da Ciência da Informação, a abordagem de problemas tem sido uma característica metodológica, como aponta Saracevic (1996, p.41), esclarecendo que

[...] Um campo é definido pelos problemas que são propostos e a ciência da informação é definida como um campo englobando tanto a pesquisa científica quanto a prática profissional, pelos problemas que propõe e pelos métodos que escolheu, ao longo do tempo, para solucioná-los.

O autor argumenta que os problemas de informação — um fenômeno da comunicação humana - não podem ser abordados dentro de uma única área da atividade científica. Por isso, torna-se necessário o desenvolvimento, na Ciência da Informação, de abordagens 
teóricas e metodológicas que favoreçam a interdisciplinaridade e permitam o relacionamento da ciência da informação com outros campos científicos. Para o autor, "trocas significantes estão acontecendo entre vários campos científicos que abordam os mesmos problemas de informação, ou semelhantes, de formas bastante diferentes. A ciência da informação definitivamente deveria unir esses campos" (SARACEVIC, 1996, p.60)

Uma proposta nesse sentido foi apresentada por Wersig durante uma conferência científica de Tampère, Finlândia (1991), cujo texto publicou no periódico Information Processing \& Management, em 1993. O autor sugere que o campo da Ciência da Informação poderia vir a tornar-se "algum tipo de sistema de navegação conceitual" para abordagem dos problemas da informação, na sociedade contemporânea (WERSIG, 1993, p.238). O autor caracteriza a Ciência da Informação como ciência pós-moderna justamente por lidar com problemas, sugerindo que o trabalho desse novo tipo de ciência não se restringiria a enunciados e conceitos, mas se ampliaria até a proposição de estratégias para solução de problemas. Para Wersig (1993, p.234), o campo da Ciência da Informação

[...] exige o desenvolvimento de perspectivas que considerem a resolução de problemas internos ao campo científico e a estruturação do campo a partir dessa visão. Por outro lado, os problemas internos acontecem por causa de complexidades e contradições presentes nas situações sociais. Então, [nosso] campo teria, normalmente, uma estrutura que hoje abordaríamos como 'caótica'. O próximo passo seria estruturar essa realidade caótica, descobrindo seus 'atratores estranhos' e suas contradições ou relações, para então contrastar a estrutura interna dos problemas do campo com as estruturas gerais. Por fim, estratégias têm que ser desenvolvidas para lidar com problemas sob condições caóticas, usando os conceitos disponíveis, ou 'atratores', para organizá-los.

Wersig (1993) apresenta sua abordagem dos problemas de informação para a Ciência da Informação com três tipos de modelos: no primeiro, propõe uma estrutura teórica orientada para a redefinição de conceitos científicos amplos, redesenhados para os propósitos do campo da ciência da informação; o segundo modelo propõe uma estrutura modelada pela reformulação científica de "inter-conceitos", também redesenhados para os propósitos do campo da ciência da informação (WERSIG, 1993, p.237).

No último dos modelos propostos, o autor sugere para a Ciência da Informação uma estrutura teórica que considere menos a formulação de leis gerais e mais a de estratégias de ação, mediante uma abordagem de entrelaçamento de conceitos científicos. Neste modelo de "rede conceitual", os conceitos fundamentais, "se constituem semelhantemente a ímãs, ou 'atratores', atraindo os materiais [teóricos ou empíricos] para fora [dos seus respectivos campos científicos] e reestruturando-os dentro da estrutura científica da informação" 
(WERSIG, 1993, p.238). Para Wersig (1993), o que se pode esperar é que os modelos sugeridos - que constituem abordagens independentes — sejam, por sua vez, "entretecidos" por indivíduos ou equipes, oportunidade em que os fios soltos encontrados nos diferentes campos poderiam ser reunidos a outros fios conceituais.

No nosso exercício, o modelo de rede conceitual constitui o contexto no qual iremos entrelaçar os indícios encontrados no território da literatura, os quais representam a produção científica sobre a temática <responsabilidade social> no campo da Ciência da Informação no Brasil, em um dado momento histórico. A figura 1, a seguir, mostra a relação entre as principais variáveis epistemológicas, teóricas e aplicadas envolvidas na nossa incursão no território da literatura: a partir do Campo científico (categoria mais ampla), nossa pesquisa buscará os indícios da produção sobre a temática <responsabilidade social> na Ciência da Informação no Brasil, especificamente nos artigos indexados pela Base de Dados Referencial de Artigos de Periódicos em Ciência da Informação.

Figura 1 - Diagrama reunindo as variáveis da pesquisa

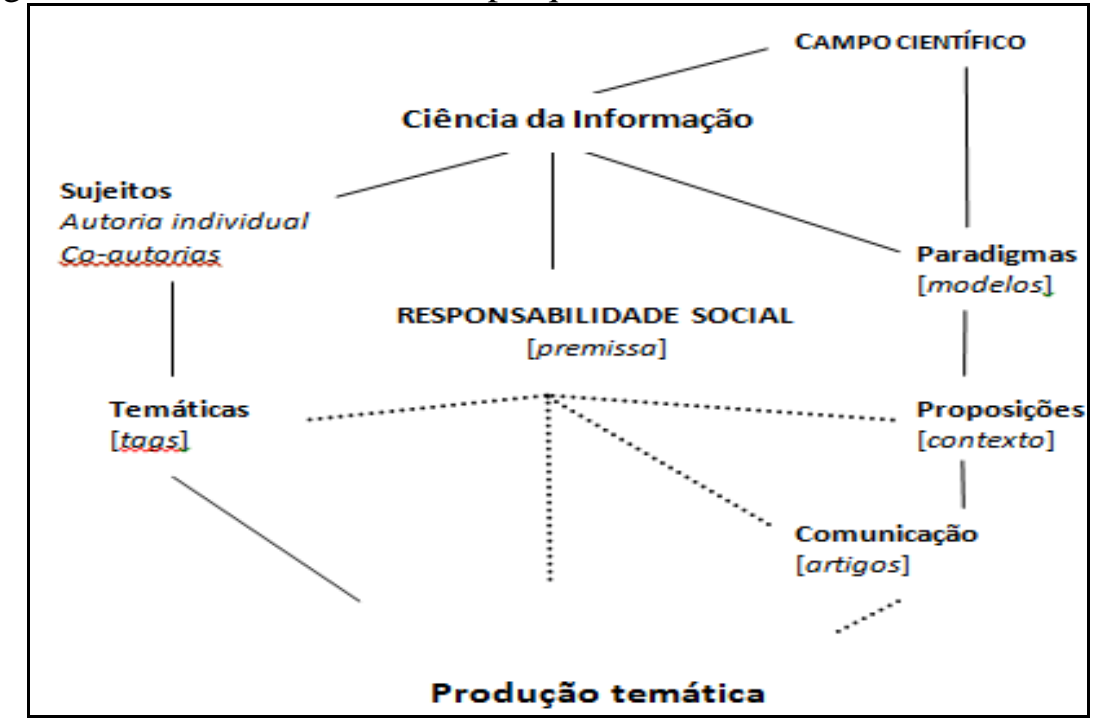

Fonte: Adaptado do modelo de rede conceitual de Wersig (1993).

Com esse mapa descritivo dos elementos da pesquisa, iniciamos nossa incursão no território da literatura no campo da Ciência da Informação no Brasil, tendo como objetivo encontrar os indícios da emergência da temática <responsabilidade social> na produção indexada pela Brapci. Nesse sentido, entendemos este exercício como narrativa da "caçada" ao nosso objeto de estudo, corroborando a proposição de Alves (1994, p.39) sobre o ofício do cientista - "caçador do invisível na realidade visível”. 


\section{Contexto}

Nesta seção, apresentamos a abordagem metodológica do nosso exercício conceitual, descrevendo os indícios da literatura sobre a temática <responsabilidade social> no campo da Ciência da Informação e os procedimentos utilizados para delimitar a amostra da pesquisa.

\subsection{Método e instrumento}

Em um ensaio publicado no final dos anos 1980, o historiador Carlo Ginzburg mostra como no final do século XIX "emergiu silenciosamente no âmbito das ciências humanas um modelo epistemológico ao qual até agora não se prestou suficiente atenção", um "paradigma indiciário", tão antigo que remontaria aos primórdios da própria evolução da humanidade (GINZBURG, 1989 p.143). O autor descreve as seriam as origens desse método indiciário:

Por milênios o homem foi caçador. Durante inúmeras perseguições, ele aprendeu a reconstruir as formas e movimentos das presas invisíveis pelas pegadas na lama, ramos quebrados, bolotas de esterco, tufos de pelos, plumas emaranhadas, odores estagnados. Aprendeu a farejar, registrar, interpretar e classificar pistas infinitesimais como fios de barba. Aprendeu a fazer operações mentais complexas com rapidez fulminante, no interior de um denso bosque ou numa clareira cheia de ciladas.

Gerações e gerações de caçadores enriqueceram e transmitiram esse patrimônio cognoscitivo. Na falta de uma documentação verbal para se por ao lado das pinturas rupestres e dos artefatos, podemos recorrer às narrativas de fábulas, que do saber daqueles remotos caçadores transmitem-nos às vezes um eco, mesmo que tardio e deformado. (GINZBURG, 1989, p.151).

Assim, esse paradigma se traduz em "um saber de tipo venatório", caracterizado pela capacidade de descrever uma realidade complexa que não seria cientificamente experimentável, a partir de dados aparentemente irrelevantes. Ginzburg (1989) acrescenta que esses dados são sempre dispostos pelo observador [caçador] de modo tal que possa se traduzir numa sequencia narrativa, cuja formulação mais simples poderia ser descrição da passagem de pessoas ou animais em algum território. Nesse sentido, o autor defende que a própria ideia de narração (contar uma história, descrever situações e comportamentos), distinta de outras formas de expressão como o sortilégio, o esconjuro ou a invocação, teria nascido numa sociedade de caçadores, a partir da experiência da decifração das pistas: “O caçador teria sido o primeiro a "narrar uma história" porque era o único capaz de ler, nas pistas mudas (se não imperceptíveis) deixadas pela presa, uma série coerente de eventos" 
(GINZBURG, 1989, p.152).

Na sua metáfora metodológica, Ginzburg (1989, p.170) compara os fios que compõem uma pesquisa desenvolvida sob o paradigma indiciário aos fios de um tapete - o que lembra a abordagem da rede conceitual de Wersig (1993). No modelo indiciário, colocados os conceitos básicos e definido o campo onde se realiza a investigação, enfim, reunidos os indícios ou pistas do objeto de estudo, o observador verá tomar forma uma "trama densa e homogênea", que será tecida no tear do quadro de referência teórico. A coerência do padrão desenhado pela visão do observador é verificável "percorrendo-se o tapete com os olhos em várias direções": o tapete é o paradigma que a cada vez que é usado, e conforme o contexto, é chamado de venatório, divinatório, indiciário ou semiótico. "Trata-se, como é claro, de adjetivos não-sinônimos, que no entanto remetem a um modelo epistemológico comum, articulado em disciplinas diferentes, muitas vezes ligadas entre si pelo empréstimo de métodos ou termos-chave" (GINZBURG, 1989, p.170).

No campo da Ciência da Informação no Brasil, em seu estudo dos sistemas de recuperação da informação, Araújo (1994) descreve um processo de busca de informação através de indícios denominado brauseio (browsing), que considera uma das modalidades de busca mais importantes em um sistema de recuperação da informação e é estudado no contexto do subsistema de estratégia de busca. A autora esclarece que o termo "browsing" é aplicado às ações de andar a esmo, ou deambular, em uma biblioteca ou centro de documentação folheando documentos ao acaso, colhendo "flashes" de informação de todos os tipos. Ainda de acordo com Araújo (1994), o termo é derivado do comportamento de busca de alimento do cervo que ao selecionar os brotos mais tenros para se alimentar o faz através de um brauseio - o que dá a esse termo a conotação de seleção de informações válidas e úteis.

Outra forma de definir o processo de brausear é "a arte de não se saber o que se quer até que se o encontre" (ARAÚJO, 1994, p.189). O brauseio é essencialmente visual e tem um forte componente de "acesso direto"; pode ser associado com formas e padrões em termos de imagens e distribuição do texto numa página ou numa tela de computador. Apesar dos critérios iniciais serem apenas parcialmente definidos, é uma atividade de busca, ocasionada por uma necessidade ou interesse de informação percebido, como no nosso caso de buscar indícios do crescimento da produção científica brasileira sobre < responsabilidade social>, no território da literatura da Ciência da Informação.

A questão é se um paradigma indiciário pode ser rigoroso. Mas, como defende Bunge (1989), o rigor teórico das ciências da natureza não seria aplicável às ciências sociais, entre elas a Ciência da Informação. Destarte, para Ginzburg (1989, p.177), esse rigor seria não 
apenas inatingível, mas, certamente, também indesejável para as formas de saber mais ligadas à experiência cotidiana, para

[...] todas as situações em que a unicidade e o caráter insubstituível dos dados são, aos olhos das pessoas envolvidas, decisivos. [Nessas situações,], o rigor flexível [...] do paradigma indiciário mostra-se ineliminável. [...] Nesse tipo de conhecimento entram em jogo [...] elementos imponderáveis: faro, golpe de vista, intuição.

Dessa forma, o paradigma indiciário pode representar um instrumento inestimável para o pesquisador que investiga um ou vários aspectos da realidade, "caçando o invisível" no visível, revelando os indícios da ordem que se esconde no caos pode adquirir sentido para um "caçador" [pesquisador]. Pois os indícios revelam o padrão que une os fios no tear conceitual, desvelando o sentido oculto no evento observado no campo da pesquisa, como esperamos demonstrar no presente exercício.

\subsection{Um olhar sobre o território}

A Base de Dados Referenciais de Artigos de Periódicos em Ciência da Informação (Brapci) representa o território da literatura para o presente exercício. A Brapci é o produto de informação do projeto de pesquisa "Opções metodológicas em pesquisa: a contribuição da área da informação para a produção de saberes no ensino superior”, cujo objetivo é subsidiar estudos e propostas na área de Ciência da Informação, fundamentando-se em atividades planejadas institucionalmente. Com esse propósito, foram identificados os títulos de periódicos da área de Ciência da Informação (CI) e indexados seus artigos, constituindo-se a base de dados referenciais. Atualmente, a Brapci disponibiliza referências e resumos de 8.303 textos publicados em 37 periódicos nacionais impressos e eletrônicos da área de CI, sendo 26 vigentes e 11 históricos (BRAPCI, 2013. Acesso em julho de 2014).

Concordamos com o texto na página inicial da Brapci, quando diz que sua construção “está contribuindo para estudos analíticos e descritivos sobre a produção editorial de uma área em desenvolvimento", como é nosso propósito neste exercício, "ao subsidiar com uma ferramenta dinâmica os alunos, professores e pesquisadores da área" (BRAPCI, 2013). Nesse sentido, certamente a Brapci "amplia o espaço documentário permitido ao pesquisador, facilita a visão de conjunto da produção na área, ao mesmo tempo [em] que revela especificidades do domínio científico", uma vez que "Os saberes e as pesquisas publicados e organizados para fácil recuperação clarificam as posições teóricas dos pesquisadores" (BRAPCI, 2013). Foi o que observamos, na prática da pesquisa no território da literatura. 
No presente exercício, buscamos artigos, em todos os campos e em todo o período (1970-2013) indexados pela Brapci, utilizando como termos de busca <responsabilidade AND social>, <responsabilidade AND social AND ciência AND informação> e <responsabilidade social>, este último um termo composto.

Os resultados consistentes para constituição de um mapa com indícios sobre a publicação de artigos no território da literatura foram obtidos na Brapci com o termo de busca <responsabilidade AND social>. Foram recuperados 78 artigos, os quais estão distribuídos num intervalo de tempo de 1978 a 2013 e incluem 11 artigos que não foram recuperados com outros dois termos de busca utilizados na pesquisa. A busca com o termo <responsabilidade AND social AND ciência AND informação> recuperou 44 artigos no período de 1985 a 2012, e a busca com o termo composto <responsabilidade social> recuperou 41 artigos no período de 1998 a 2012, mostrando-se a menos produtiva.

Dentre os 78 artigos recuperados com o termo de busca mais produtivo, selecionamos 40 artigos cujos temas consideramos pertinentes ao escopo deste exercício, num intervalo de tempo de 1999 a 2012. Consideramos, então, que esta amostra assim constituída representa o território da literatura de interesse pata nossa pesquisa, o locus onde seria mais produtivo buscar os indícios da emergência de produção científica sobre a temática <responsabilidade social> no campo da Ciência da Informação, no Brasil.

A seguir, apresentamos uma imagem do quadro de tags (Termos associados à descrição de busca para filtrar informações relevantes) da Brapci relativo aos resultados da busca usando o termo <responsabilidade AND social>, em todos os campos e em todo o período (1970-2013):

Figura 2 - Tags associadas aos resultados de busca

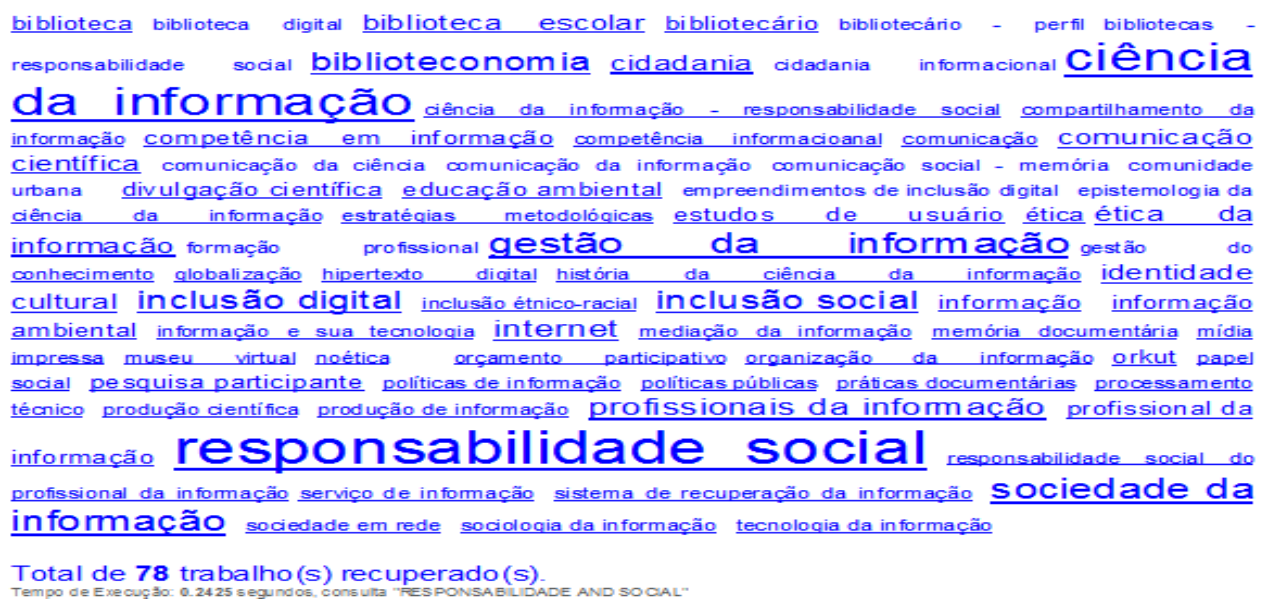

Fonte: Dados da pesquisa, 2013. 
Dentre as tags que representam os termos associados à descrição de busca para filtrar informações relevantes, destacamos como relevantes para a pesquisa os termos <ciência da informação> e <responsabilidade social> e <biblioteconomia>; num segundo nível, identificamos os temos <gestão da informação>, <inclusão social> e <sociedade da informação>, e ainda os termos <biblioteca escolar>, <comunicação científica>, <ética da informação>, <inclusão digital>, <internet>, <jornalismo> e <profissionais da informação>; num nível que descrevemos, a seguir, como de "aplicação teórica", observamos dispersão da temática por inúmeros termos, destacando-se, 〈biblioteca〉, 〈bibliotecário〉, <competência em informação>, <divulgação científica> e <estudos de usuários>.

A partir desses indícios, observados no território da literatura, organizamos uma classificação das temáticas representadas nas tags à luz das ações de informação, como propõe González de Gómez (2003a), com vistas a sua interpretação no contexto da produção sobre < responsabilidade social da CI> indexada na Brapci. Trata-se de uma figura elaborada a partir dos indícios da temática, cujos níveis descritivos relacionamos ao contexto do domínio das ações e finalidades das ações de informação, como segue:

Figura 3 - Organização e relação das tags com os domínios das ações de informação

\begin{tabular}{|c|c|c|c|}
\hline \multicolumn{3}{|c|}{ Domínios e finalidades das ações de informação } & Níveis descritivos das tags \\
\hline$L E G E I N^{2}$ & $\begin{array}{l}\text { Açőes relacionais } \\
\text { Inter-Meta-Pós- } \\
\text { mediáticas. } \\
\text { Atividades sócio- } \\
\text { culturais. }\end{array}$ & $\begin{array}{l}\text { Transformar a informação } \\
\text { e a comunicação que } \\
\text { orientam o agir coletivo. }\end{array}$ & $\begin{array}{l}\text { Nivel epistemológico } \\
\text { CIÊNCIA DA INFORMAÇÃO } \\
\text { RESPONSABILIDADE SOCIAL }\end{array}$ \\
\hline POIESIS & $\begin{array}{l}\text { Açőes formativas } \\
\text { ou finalistas. } \\
\text { Atividades } \\
\text { heurísticas e de } \\
\text { inovação. }\end{array}$ & $\begin{array}{l}\text { Transformar o } \\
\text { conhecimento para } \\
\text { transformar o mundo }\end{array}$ & $\begin{array}{l}\text { Nivel teórico } \\
\text { BIBLIOTECONOMIA } \\
\text { GESTÃO DA INFORMAÇÃO } \\
\text { INCLUSÃO SOCIAL } \\
\text { SOCIEDADE DA INFORMACÃO }\end{array}$ \\
\hline$P R A ́ X I S^{4}$ & $\begin{array}{l}\text { Ações de mediação. } \\
\text { Atividades sociais } \\
\text { de Controle, } \\
\text { Monitoramento e } \\
\text { Coordenação. }\end{array}$ & $\begin{array}{l}\text { Transformar o mundo } \\
\text { social ou natural. }\end{array}$ & $\begin{array}{l}\text { Nivel da aplicação } \\
\text { BIBLIOTECA ESCOLAR } \\
\text { COMUNICAÇÃO CIENTÍFICA } \\
\text { ÉTICA DA INFORMAÇÃO } \\
\text { INCLUSÃO DIGITAL } \\
\text { PROFISSIONAIS DA INFORMAÇÃO } \\
\text { BIBLIOTECA } \\
\text { BIBLIOTECÁRIO } \\
\text { COMPETÊNCIA EM INFORMAÇÃO } \\
\text { ESTUDOS DE USUÁRIOS } \\
\text { DIVULGAÇÃO CIENTÍFICA }\end{array}$ \\
\hline
\end{tabular}

Fonte: Dados da pesquisa, 2013. Baseado em González de Gómez, 2003a. 
Legein: "[...] quando uma ação de informação intervém em [uma] outra [...], duplicando o espaço de realização [desta, de modo a ampliar as] formas de descrição, da facilitação, do controle ou do monitoramento, [...] realizadas por sujeitos articuladores ou relacionantes." (GONZÁLEZ DE GÓMEZ, 2003a, p. 36).

Poiesis: "[...] quando a ação de informação no contexto formativo é gerada por sujeitos sociais heurísticos ou 'experimentadores', transformando os modos culturais de agir e de fazer, nas artes, na política, na ciência, na indústria e no trabalho, iniciando um novo domínio informacional." (GONZÁLEZ DE GÓMEZ, 2003a, p. 36).

Práxis: No campo científico, entendemos como uma prática profissional em que os sujeitos sociais atuam a partir de uma teoria que é a base para sua ação no mundo.

Esse quadro conceitual-temático apresenta trilhas a serem seguidas na nossa incursão pelo território da literatura, um mapa que nos auxiliará na identificação das abordagens da temática <responsabilidade social da $\mathrm{CI}>$, nos artigos indexados na Brapci. A seguir, apresentamos um quadro com o quantitativo de artigos selecionados como pertinentes e relevantes à temática, distribuídos pelos 15 periódicos que os publicaram no período 19992012:

Quadro 1 - Periódicos: quantidade de artigos e ano da publicação

\begin{tabular}{|l|c|c|}
\hline \multicolumn{1}{|c|}{ PERIÓDICOS } & $\begin{array}{c}\text { QTDE. } \\
\text { ARTIGOS }\end{array}$ & $\begin{array}{c}\text { ANOS DE } \\
\text { PUBLICAÇÃO }\end{array}$ \\
\hline Ciência da Informação $^{2}$ & 5 & $2006 ; 2004 ; 2003 ; 2002$ \\
\hline Perspectivas em CI & 4 & $2012 ; 2011 ; 2009 ; 2008$ \\
\hline Datagramazero & 4 & $2008 ; 2006 ; 2004 ; 2000$ \\
\hline Biblionline & 4 & $2011 ; 2010 ; 2009 ; 2005$ \\
\hline Transinformação ${ }^{3}$ & 4 & $2005 ; 2004 ; 1999$ \\
\hline Encontros Bibli & 3 & $2008 ; 2007 ; 2003$ \\
\hline Informação \& Sociedade $_{\text {Em Questão }}$ & 2 & $2008 ; 2004$ \\
\hline Revista Digital de Biblioteconomia e CI & 2 & $2012 ; 2011$ \\
\hline Informação \& Informação & 2 & $2010 ; 2005$ \\
\hline Gestão \& Conhecimento & 1 & $2012 ; 2001$ \\
\hline Ponto de Acesso & 1 & 2012 \\
\hline Brazilian Journal of Information Science & 1 & 2010 \\
\hline Educação Temática Digital & 1 & 2009 \\
\hline Inclusão social & 1 & 2003 \\
\hline TOTAL DE ARTIGOS & 50 & 2007 \\
\hline
\end{tabular}

Fonte: Dados da pesquisa, 2013. $\mathrm{N}$ = Número de periódicos.

Observe-se que no primeiro ano do período identificado na amostra (1999 a 2012) foi publicado apenas um artigo, enquanto no último ano do período foram publicados quatro artigos, evidenciando um processo de emergência e crescimento constante a partir de 2008

\footnotetext{
${ }^{2}$ Em 2006 publicou dois artigos.

${ }^{3}$ Em 1999 publicou dois artigos.
} 
que consideramos significativo para nossa hipótese de trabalho. O periódico Transinformação foi quem primeiro publicou um artigo diretamente relacionado à temática em estudo, o qual tem o tema <responsabilidade social da Ciência da Informação> no próprio título. Contudo, no período publicou apenas outros dois artigos sobre a temática, perfazendo quatro artigos publicados no período. Outros periódicos que publicaram quatro artigos também apresentam dispersão de eventos no tempo: Ciência da Informação, que publicou seu último artigo sobre a temática em 2006; e Datagramazero, que publicou seu último artigo sobre a temática em 2008 .

Dentre os periódicos que mais publicaram sobre a temática destacamos Perspectivas em Ciência da Informação, que embora tenha publicado seu primeiro artigo apenas em 2008 vem mantendo um ritmo constante e consistente de publicações sobre a temática (quatro artigos em cinco anos); e Biblionline, que vem acompanhando esse ritmo, tendo publicado o primeiro artigo sobre a temática em 2005 e o mais recente em 2011 (quatro artigos em seis anos).

A seguir, adentramos nas trilhas que levam aos autores e à revelação das abordagens dos artigos, no território da literatura indexada na Brapci.

\section{Autores e temas revelados}

Nesta seção, descrevemos os resultados da nossa caçada no território da literatura sobre a temática <responsabilidade social> na Ciência da Informação, quais autores se apresentaram nas trilhas da pesquisa, os que caminham sozinhos ou em dupla ou em equipe, quais os problemas que abordaram e os resultados obtidos em suas respectivas caçadas, nos domínios e níveis descritos na figura 3, a qual representa o mapa que orienta nosso exercício.

A seguir, apresentamos um quadro com os 50 autores identificados na amostra, o número de artigos publicados por autores individuais e/ou em co-autoria e o número de autores ou co-autores por artigo. Observa-se que quase a metade dos artigos foi publicada por duplas de autores: são 17 duplas de autores, mas nessa amostra apenas duas duplas se repetem, tendo publicado dois artigos, cada uma delas. 
Quadro 2 - Autores e co-autorias: quantidade e número de artigos

\begin{tabular}{|c|c|c|c|}
\hline $\begin{array}{l}\text { AUTORES PRINCIPAIS } \\
\text { OU INDIVIDUAIS }\end{array}$ & CO-AUTORES & $\begin{array}{c}\text { Qtde. } \\
\text { autores }\end{array}$ & $\begin{array}{l}\text { Qtde. } \\
\text { artigos }\end{array}$ \\
\hline AQUINO, M. de A.; & $\begin{array}{l}\text {; COSTA, A.R.F.; WANDERLEY, A.C.C.; BEZERRA, L.T.S.; LIMA, } \\
\text { I.F. de; SANTIAGO, S.M. }\end{array}$ & 6 & 1 \\
\hline BEZERRA, M.A.; & ; ARAÚJO, E.A. de A. & 2 & 2 \\
\hline CHALAÇA, A.M.; & ; FREIRE, I.M.; MIRANDA, M.L.C. de & 3 & 1 \\
\hline CUNHA, M.V. da & Individual & 1 & 1 \\
\hline CUSTÓDIO, C.Q. & Individual & 1 & 1 \\
\hline ESPÍRITO SANTO, C. do; & _ FREIRE, I.M. & 2 & 1 \\
\hline FARIAS, C.M.; & ; VITORINO, E.V. & 2 & 1 \\
\hline FARIAS, M.G.G.; & ; FREIRE, I.M. & 2 & 2 \\
\hline FERNANDES, G. & Individual & 1 & 1 \\
\hline FONSECA, J.S. da; & $\ldots$; GARCIA, J.C.R. & 2 & 1 \\
\hline FREIRE, G.H. de A. & Individual & 1 & 1 \\
\hline FREIRE, I.M. & Individual & 1 & 7 \\
\hline FREIRE, I.M.; & ; ARAUJO, V.M.R. H. de & 2 & 1 \\
\hline FREIRE, I.M.; & ; NATHANSOHN, B.M.; ESPÍRITO SANTO, C. do; TAVARES, C. & 4 & 1 \\
\hline FREIRE, I.M.; & ; NÓBREGA, N.G. da; BADINI, S.B.; ARAÚJO, V.M.R.H. de & 4 & 1 \\
\hline GARCIA, J.C.R. & Individual & 1 & 1 \\
\hline GARCIA, J.C.R.; & _ _ TARGINO, M. DAS G.; DANTAS, E.R.F. & 3 & 1 \\
\hline GONZÁLEZ DE GÓMEZ, M.N. & Individual. & 1 & 1 \\
\hline LIMA, A.P. de; & _ $;$ BRASILEIRO, F.S.;MENEZES, I.P. de; GARCIA, J.C.R. & 4 & 1 \\
\hline LIRA, A.S.X. de; & ; OLIVEIRA, J.M. de & 2 & 1 \\
\hline LOPES, A. DE A.; & ; FREIRE, I.M. & 2 & 1 \\
\hline MORAES, M.B. de; & ; LUCAS, E. de O. & 2 & 1 \\
\hline NASCIMENTO, J.C.N.; & $\ldots \ldots$; FREIRE, G.H. de A. & 2 & 1 \\
\hline NATHANSOHN, B.M.; & _.; FREIRE, I.M. & 2 & 1 \\
\hline PEREIRA, E.C.; & ; RUTINA, R. & 2 & 1 \\
\hline SANTANA, V.A.; & ; AQUINO, M. DE A. & 2 & 1 \\
\hline SERAFIM, L.A.; & ; FREIRE, G.H. DE A. & 2 & 1 \\
\hline SILVA, N. dos S.; & ; SILVA, M.B. da & 2 & 1 \\
\hline SOUSA, P. de T.C. de & Individual & 1 & 1 \\
\hline TARAPANOFF, $\mathrm{K}$. & Individual & 1 & 1 \\
\hline TAVARES, C.; & _ FREIRE, I.M. & 2 & 1 \\
\hline VALENTIM, M.L.P.; & _ $;$ MISCHIATI, A.C. & 2 & 1 \\
\hline
\end{tabular}

Fonte: Dados da pesquisa, 2013. Em destaque: os autores mais produtivos.

No conjunto de autores que publicaram no período de 1999 a 2012, predominam os que publicaram apenas um artigo no intervalo de 13 anos coberto pela pesquisa, como mostra o quadro 2. Os artigos publicados por duplas de autores, as quais só se repetem duas vezes, apontam para comunicação de resultados de pesquisas no campo da Ciência da Informação, muito provavelmente em nível de formação (graduação ou pós-graduação).

Nesse conjunto de autores, destaca-se um que publicou sete artigos no período, individualmente ou com coautores diversos; outros dois autores também publicaram individualmente e em dupla ou equipe com coautores; há cinco autores que publicaram artigos individualmente, mas o fizeram apenas uma vez durante todo o período; duas duplas de autores publicaram dois artigos no período e os demais autores publicaram, individualmente ou em coautoria, apenas um artigo no período.

Destarte, identificamos uma dispersão na autoria dos artigos, sendo o número de autores $25 \%$ maior do que o número de artigos produzidos, muito embora a característica marcante seja a autoria em dupla. Ademais que o crescimento consistente e constante da publicação de artigos sobre a temática <responsabilidade social> em periódicos da Ciência da 
Informação no Brasil, como já comentamos nesta seção, apontam para um campo de pesquisa promissor e instigante.

Para identificar o que dizem os autores na amostra, buscamos os indícios da temática <responsabilidade social> da Ciência da Informação nos títulos, resumos e descritores dos artigos da amostra. O quadro a seguir, apresenta os autores e o resumo das respectivas temáticas abordadas nos artigos:

Quadro 3 - Temas: autores e abordagem dos artigos

\begin{tabular}{|c|c|}
\hline \begin{tabular}{|l} 
AUTORES \\
\end{tabular} & TEMAS ABORDADOS \\
\hline $\begin{array}{l}\text { AQUINO, M. de A.; COSTA, A.R.F.; WANDERLEY, } \\
\text { A.C.C.; BEZERRA, L.T.S.; LIMA, I.F. de; SANTIAGO, } \\
\text { S.M. }\end{array}$ & RS profissionais da informação; Inclusão social \\
\hline BEZERRA, M.A.; ARAÚJO, E.A. de A. & $\begin{array}{l}\text { Discussão sobre RS e ética nas redes sociais; Relato de } \\
\text { pesquisa no Orkut }\end{array}$ \\
\hline BEZERRA, M.A.; ARAÚJO, E.A. de A. & $\begin{array}{l}\text { Discussão sobre RS e ética nas redes sociais; Relato de } \\
\text { pesquisa no Orkut }\end{array}$ \\
\hline CHALAÇA, A.M.; FREIRE, I.M.; MIRANDA, M.L.C. de & $\begin{array}{l}\text { RS do profissional bibliotecário; Inclusão social; } \\
\text { Memória social }\end{array}$ \\
\hline CUNHA, M.V. da & RS do bibliotecário; Sociedade do conhecimento \\
\hline CUSTÓDIO, C.Q. & Revisão de literatura; RS do profissional da informação \\
\hline ESPÍRITO SANTO, C. do; FREIRE, I.M. & $\begin{array}{l}\text { RS da CI; Inclusão digital; Inclusão social; Identidade } \\
\text { cultural }\end{array}$ \\
\hline FARIAS, C.M.; VITORINO, E.V. & RS profissionais da informação \\
\hline FARIAS, M.G.G.; FREIRE, I.M. & $\begin{array}{l}\text { RS da CI; Ação de informação para intervenção em } \\
\text { comunidade urbana; Inclusão digital; Inclusão social }\end{array}$ \\
\hline FARIAS, M.G.G.; FREIRE, I.M. & $\begin{array}{l}\text { RS da CI; Ação de informação para intervenção em } \\
\text { comunidade urbana; Inclusão digital. Inclusão social }\end{array}$ \\
\hline FERNANDES, G. & $\begin{array}{l}\text { Ações de informação e práticas documentárias; } \\
\text { Profissionais da informação }\end{array}$ \\
\hline FONSECA, J.S. da; GARCIA, J.C.R. & $\begin{array}{l}\text { RS e ética do profissional da informação; relato de } \\
\text { pesquisa sobre práticas em bibliotecas de IES }\end{array}$ \\
\hline FREIRE, G.H. de A. & $\begin{array}{l}\text { RS da CI; Comunicação da informação em redes de } \\
\text { aprendizagem }\end{array}$ \\
\hline FREIRE, I.M. & $\begin{array}{l}\text { RS e ética dos profissionais da informação; Sociedade em } \\
\text { rede; Democratização da informação; Inclusão social }\end{array}$ \\
\hline FREIRE, I.M. & $\begin{array}{l}\text { RS da CI; Inclusão digital; Inclusão social; Memória } \\
\text { cultural }\end{array}$ \\
\hline FREIRE, I.M. & $\begin{array}{l}\text { RS da CI; Inclusão digital; Inclusão social; Identidade } \\
\text { cultural }\end{array}$ \\
\hline FREIRE, I.M. & RS da CI; Rede conceitual; Consciência possível \\
\hline FREIRE, I.M. & $\begin{array}{l}\text { RS da CI; RS dos profissionais da informação; Inclusão } \\
\text { digital; Inclusão social }\end{array}$ \\
\hline FREIRE, I.M. & $\begin{array}{l}\text { RS da CI; Rede de projetos; Sistema de recuperação da } \\
\text { informação }\end{array}$ \\
\hline FREIRE, I.M. & $\begin{array}{l}\text { RS da CI; História da CI; Consciência possível para } \\
\text { comunicação da informação sobre a RS da CI }\end{array}$ \\
\hline FREIRE, I.M.; ARAUJO, V.M.R. H. de & RS da CI; RS dos profissionais da informação \\
\hline $\begin{array}{l}\text { FREIRE, I.M.; NATHANSOHN, B.M.; ESPÍRITO SANTO, } \\
\text { C. do; TAVARES, C. }\end{array}$ & $\begin{array}{l}\text { RS da CI; Estudos de usuários na perspectiva da RS da } \\
\text { CI }\end{array}$ \\
\hline $\begin{array}{l}\text { FREIRE, I.M.; NÓBREGA, N.G. da; BADINI, S.B.; ARAÚJO, } \\
\text { V.M.R.H. de }\end{array}$ & RS da CI; Inclusão social; Relato de pesquisa \\
\hline GARCIA, J.C.R. & RS profissionais da informação \\
\hline GARCIA, J.C.R.; TARGINO, M. DAS G.; DANTAS, E.R.F. & $\begin{array}{l}\text { Discussão teórica acerca da CI e da RS; Análise conteúdo } \\
\text { de dissertações de mestrado no PPGCI UFPB }\end{array}$ \\
\hline GONZÁLEZ DE GÓMEZ, M.N. & RS campo científico; programas de pesquisa \\
\hline $\begin{array}{l}\text { LIMA, A.P. de; BRASILEIRO, F.S.;MENEZES, I.P. de; } \\
\text { GARCIA, J.C.R. }\end{array}$ & $\begin{array}{l}\text { Revisão de literatura; Ética e RS na atualidade; Produção } \\
\text { científica no âmbito das IES }\end{array}$ \\
\hline
\end{tabular}




\begin{tabular}{|l|l|}
\hline LIRA, A.S.X. de; OLIVEIRA, J.M. de & RS da CI; Política de informação; Inclusão social \\
\hline LOPES, A. DE A.; FREIRE, I.M. & RS da CI; Inclusão social; Orçamento participativo \\
\hline MORAES, M.B. de; LUCAS, E. de O. & $\begin{array}{l}\text { Análise dos currículos de cursos de Biblioteconomia; } \\
\text { Identificação de questões referentes à RS }\end{array}$ \\
\hline NASCIMENTO, J.C.N.; FREIRE, G.H. de A. & RS da CI; Política de informação para inclusão social \\
\hline NATHANSOHN, B.M.; FREIRE, I.M. & RS da CI; Ciberespaço; Estudo de usuários \\
\hline PEREIRA, E.C.; RUTINA, R. & RS profissionais da informação \\
\hline SANTANA, V.A.; AQUINO, M. DE A. & $\begin{array}{l}\text { RS e ética dos profissionais da informação; Inclusão } \\
\text { social de afrodescendentes }\end{array}$ \\
\hline SERAFIM, L.A.; FREIRE, G.H. DE A. & Ação de responsabilidade social da CI; Inclusão social \\
\hline SILVA, N. dos S.; SILVA, M.B. da & $\begin{array}{l}\text { Relato de experiência. Contribuição da organização da } \\
\text { informação para o papel social da Biblioteca }\end{array}$ \\
\hline SOUSA, P. de T.C. de & $\begin{array}{l}\text { Utilização do capital social e da gestão do conhecimento } \\
\text { na perspectiva da RS; CI como CS }\end{array}$ \\
\hline TARAPANOFF, K. & RS profissionais da informação \\
\hline TAVARES, C.; FREIRE, I.M. & $\begin{array}{l}\text { RS da CI; Estudo de assimilação da informação } \\
\text { ambiental }\end{array}$ \\
\hline VALENTIM, M.L.P.; MISCHIATI, A.C. & $\begin{array}{l}\text { RS do profissional bibliotecário em unidades de } \\
\text { informação }\end{array}$ \\
\hline
\end{tabular}

Fonte: Dados da pesquisa, 2013.

As temáticas que sobressaem nos descritores dos artigos recuperados na Brapci que constituem nossa amostra, no período delimitado na pesquisa, são <responsabilidade social> e <ciência da informação>; às quais se seguem <profissionais da informação>, <inclusão social> e <responsabilidade social da ciência da informação>, esta última sempre associada à autora mais produtiva desse conjunto (exceto em uma ocorrência).

Essas temáticas podem ser reunidas e interpretadas em nível do mapa dos domínios e finalidades das ações de informação, que criamos a partir dos domínios das ações de informação e níveis descritivos das tags, a saber:

a) no domínio da legein, em nível epistemológico das ações estruturantes, inter-metapós-midiáticas, realizadas por sujeitos articuladores ou relacionantes, destacamos os descritores que foram associadas em maior número ao termo de busca <responsabilidade social> e <ciência da informação>. São ações regulatórias, em nível da análise e proposição de modelos de ações para política e gestão de informações científicas e tecnológicas.

b) no domínio da poiesis, em nível teórico das ações formativas ou finalistas realizadas por sujeitos heurísticos ou experimentadores, observamos fortes indícios das temáticas <gestão da informação> e <inclusão social>. São ações mimeomórficas, de desenvolvimento de abordagens conceituais e estruturas tecnológicas aplicáveis á solução de problemas de informação, em diversos contextos e situações.

c) no domínio da práxis, em nível da aplicação da epistemologia e da teoria no campo profissional, observamos claros indícios de abordagens que remetem, entre outras, às temáticas <biblioteca escolar>, <comunicação científica>, <inclusão digital> e <competências em informação >. São ações polimórficas, em nível das diversas narrativas das diversificadas 
ações de aplicação de modelos e tecnologias a processos e procedimentos técnicos, no campo da informação.

Em nível da aplicação, dentre os temas abordados nos artigos da amostra, observamos a dispersão característica das inúmeras aplicações de modelos de abordagem baseados na premissa da <responsabilidade social>, como sugerem os temas <profissionais da informação>, <profissional bibliotecário>, <estudos de usuários>, <inclusão digital>, <política de informação>, <memória cultural>, 〈sistema de recuperação da informação>, $<$ história da CI>, <programas de pesquisa>, dentre outros.

Como seria de esperar, há grande dispersão de termos relacionados aos artigos recuperados na Brapci no domínio da práxis, dos problemas relacionados a aspectos éticos e técnicos da atuação acadêmica e profissional e do compromisso com usuários, na sociedade. Pois é na reunião entre teoria e prática que as abordagens se tornam (ou não) reais, e é na lida com os problemas de informação que surgem soluções que resultam do diálogo profícuo entre conceito e instrumento.

Desse modo, o domínio da práxis lança seus fios conceituais na direção do domínio da poiesis, onde se delineiam as abordagens propriamente teóricas de que tratam as narrativas expressas nos artigos recuperados na Brapci. E é deste domínio que, mais adiante, serão lançados os fios à legein - espaço da discussão epistemológica sobre a pertinência e a relevância da produção científica sobre a temática da <responsabilidade social>, no campo da Ciência da Informação, no Brasil.

\section{Considerações finais}

Assim, entendemos que nossa incursão no território da literatura sobre <responsabilidade social>, mediante recuperação de artigos indexados na Brapci do período de 1970 a 2012, confirma a hipótese da emergência de produção científica que aborda essa problemática, no Brasil. E podemos caracterizar essa produção como "emergente", considerando que os indícios apontam para sua contemporaneidade: é praticamente inexistente até 1999 e começa a se tornar consistente a partir de 2004.

Os indícios revelam que os periódicos incluídos na amostra da pesquisa que mais publicaram sobre a temática <responsabilidade social>, no período de 1999 a 2012, foram: Ciência da Informação (cinco artigos, de 2002 a 2006); Perspectivas em Ciência da Informação (quatro artigos, de 2008 a 2012); Datagramazero (quatro artigos, de 2000 a 2008); Bibionline (quatro artigos, de 2005 a 2009); Transinformação (quatro artigos, de 1999 
a 2005) e Encontros Bibli (três artigos, de 2003 a 2008).

Nossa pesquisa encontrou 50 autores que produzem literatura sobre problemas abordados na perspectiva da <responsabilidade social> no campo da Ciência da Informação. Dentre os autores, oito produziram individualmente, mas grande maioria dos artigos foi produzida por dupla de autores. Neste caso, podemos supor que se tratar de comunicação de resultados de pesquisas em nível de graduação ou pós-graduação; contudo, seria necessário buscar indícios para corroborar essa hipótese em metadados ocultos pelo sistema de indexação da Brapci, tais como vinculação institucional dos autores e finalidade das pesquisas.

Concluímos que os 40 artigos que constituem nossa amostra no presente exercício, abordam a problemática nos termos representados nas tags, como pudemos observar brauseando títulos, resumos e descritores, e neles identificando indícios da emergência de produção científica sobre <responsabilidade social> e <ciência da informação>, abrangendo também <biblioteconomia>, 〈gestão da informação>, <inclusão social>, <sociedade da informação>, <comunicação científica〉, 〈bibliotecas〉, 〈bibliotecários〉, <estudos de usuários>, <unidades de informação> e <profissionais da informação>. Esses indícios foram relacionados aos domínios e finalidades das ações de informação, aqui consideradas como a publicação de artigos sobre a temática no período de 1999 a 2012.

De modo que consideramos ter atingido nosso objetivo, nessa incursão no território da literatura da Ciência da Informação, quando buscamos os indícios da emergência de produção brasileira sobre a temática <responsabilidade social>, a partir de artigos de periódicos indexados pela Brapci.

Destarte, nosso exercício, no contexto que tecemos e com os instrumentos utilizados, encontrou evidências plausíveis e aceitáveis de que essa temática já conta com o interesse de um núcleo de pesquisadores, que aplicam essa abordagem a diversos problemas de informação na sociedade brasileira. Mas somente o tempo e novas pesquisas nos dirão se esta trilha permanecerá produtiva, no campo da Ciência da Informação.

\section{Referências}

ARAUJO, V.M.R.H. de. Sistemas de recuperação da informação: nova abordagem teórico-conceitual. 1994. Tese (Doutorado em Com. e Cult.). Rio de Janeiro: UFRJ, 1994.

FREIRE, I.M. Temática "Responsabilidade social” na literatura da Ciência da Informação indexada pela Brapci. In: ENANCIB - Encontro Nacional de Pesquisa em Ciência da Informação, 28/out. a 1/nov. 2013. XIV ENANCIB. Anais... Florianópolis: UFSC, 2013. 
FREIRE, I.M. Caracterização das ações de informação no Laboratório de Tecnologias Intelectuais - LTi. Tendências da Pesquisa Brasileira em Ciência da Informação, v.5, n.1, jan./dez. 2012.

FREIRE, I.M. A responsabilidade social da Ciência da Informação e/ou O olhar da consciência possível sobre o campo científico. 2001. Tese (Dout. Ci. Inf.). Rio de Janeiro: UFRJ, 2001.

GINZBURG, C. Mitos, emblemas, sinais: morfologia e história. São Paulo: Companhia das Letras, 1989.

GONZÁLEZ DE GÓMEZ, M.N. Novas fronteiras tecnológicas das ações de informação: questões e abordagens. Ciência da Informação, v.33, n.1, p. 55-67, jan./abr. 2004.

GONZÁLEZ DE GÓMEZ, M.N. As relações entre ciência, Estado e sociedade: um domínio de visibilidade para as questões da informação. Ciência da Informação, v.32, n. 1, p. 60-76, jan./abr. 2003b.

GONZÁLEZ DE GÓMEZ, M.N. Escopo e abrangência da Ciência da Informação e a PósGraduação na área: anotações para uma reflexão. Transinformação, v.15, n.1, p.31-43, 2003a.

POPPER, K.R. Conjectures and refutations: The growth of scientific knowledge. 4 ed. New York: Basic Books, 1972.

SARACEVIC, T. Ciência da Informação: origem, evolução e relações. Perspectivas em Ciência da Informação, v.1, n.1, 1996.

UFPR. Base de Dados Referencial de Artigos de Periódicos em Ciência da Informação Brapci. Disponível em: <http://www.brapci.inf.br/>. Acesso em: 7 set. 2014.

WERSIG, G. Information science: the study of postmodern knowledge usage. Information Processing \& Management, v.29, n.2, 1993.

WERSIG, G., NEVELING, U. The phenomena of interest to information science. The Information Scientist. v.9, n.4, 1975. 